DOI: http://dx.doi.org/10.22483/2177-5796.2017v19n3p669-688

\title{
As (cada vez mais) novas tecnologias inseridas no cotidiano escolar sob a ótica docente
}

\author{
Leandro Petarnella \\ Leandro Nhoncance
}

Resumo: Este trabalho objetivou desvelar a percepção e/ou o entendimento docente sobre os atuais desafios para a utilização novas tecnologias em práticas pedagógicas no cotidiano escolar. Para tanto, utilizou-se da técnica da análise do conteúdo como metodologia de análise aplicada às respostas de 07 professores atuantes em uma escola da rede pública de ensino em São Paulo/SP. A interpretação e discussão dos dados permitiu-nos concluir que a inovação nas práticas pedagógicas, segundo os entrevistados ainda depende, intrinsicamente, do apoio e de ações governamentais que objetivem tal finalidade. Ainda: os resultados apontam para uma falsa percepção docente de que as novas tecnologias não são capazes de promover mudanças nas práticas pedagógicas.

Palavras-chave: Cotidiano escolar. Novas tecnologias. Práticas pedagógicas.

\section{The (increasingly) new technologies inserted in the school daily life under the teacher perspective}

\begin{abstract}
This work aimed to unveil the perception and / or the teacher understanding of the current challenges to use new technologies in pedagogical practices in school everyday. To do so, we used the content analysis technique as an analysis methodology applied to the responses of 07 teachers working in a public school system in São Paulo / SP. The interpretation and discussion of the data allowed us to conclude that innovation in pedagogical practices, according to those interviewed, still depends, intrinsically, on the support and governmental actions that aim at this purpose. Yet: the results point to a false teacher's perception that new technologies are not capable of promoting changes in pedagogical practices.
\end{abstract}

Keywords: School daily. New technologies. Pedagogical practices. 


\title{
1 Introdução
}

\begin{abstract}
A educação formal perdeu seu poder legitimador do processo formativo pessoal e, por isso mesmo, suas ações, desde o final da idade média e início do período moderno, tornam-se repetição de processos cuja sociedade já se saturou. Remakes de filmes a muito já vistos (PETARNELLA, 2011, p. 98).

O Documentos Google dá vida aos seus documentos com ferramentas de edição e estilo para facilitar a formatação de textos e parágrafos. Escolha entre centenas de fontes e adicione links, imagens e desenhos. E todos esses recursos são gratuitos (GOOGLE, 2017).
\end{abstract}

As cada vez mais novas tecnologias se fazem presente na maior parte das atividades humanas. Na sala de aula, esta afirmação não se faz diferente desvelando, por isso mesmo, muitos desafios e contradições frente ao modelo de educação secularmente instituído. É claro que podemos considerar a riqueza do cotidiano escolar justamente nos desafios e nas contradições que ele nos apresenta. Mas, ao mesmo tempo, os atores sociais envolvidos nas resoluções dos referidos nem sempre se dão conta da polifonia gerada e enredada pelo amadurecimento cultural que, hodiernamente, se atrela a utilização dos recursos tecnológicos.

Ao refletirmos, então, sobre o status quo da sociedade atual, sobre a utilização dessas cada vez mais novas tecnologias em sala de aula, sobre o papel docente no desenvolvimento das potencialidades humanas e na disseminação da herança cultural secularmente instituída, encontramos um hiato a ser preenchido. Isto porque, se por um lado temos um sistema de transmissão cultural já instituído moldado e marcado por uma lógica secular, onde o professor transmissor assume-se como o sujeito detentor do conhecimento e visualiza o ensino como um dom, do outro, temos os alunos mais conectados, com acesso as informações de forma instantânea, o que, por sua vez, o permite utilizar seu cérebro coletivo virtual onde e quando quiser. É o interstício que ora se apresenta entre o sujeito disciplinado, padronizado, dócil e regulado pela modernidade, preparado para o trabalho na indústria, ou, nas palavras de Sibilia (2012), para as "paredes e os engendramentos produtivos" e o sujeito hodierno, líquido, incerto, rizomático, preparado para (com) viver em uma sociedade informacional cuja característica se firma, ainda com Sibilia, mais por uma rede do que pelas fissuradas paredes herdadas da modernidade. 
O interstício apresentado, se arma e se mostra no cotidiano escolar de maneira fragmentada, mas, ao mesmo tempo, contundente: entre o giz e a lousa, se abrem novas possibilidades como a tela ou o celular. No trabalho docente, os livros, as apostilas, as avaliações e os planos de aula se entrecruzam com a informação de bases de dados eletrônicas, com cursos e sistemas online de aprendizagem e formulários para avaliações digitais. É justamente, então, neste interstício, que se firma o objetivo do presente trabalho: desvelar a percepção e/ou o entendimento docente sobre os atuais desafios para a utilização novas tecnologias no cotidiano escolar. Para tanto, parte da análise do conteúdo das respostas de 07 professores atuantes em uma escola da rede pública de ensino em São Paulo/SP. Os dados apresentados foram discutidos a partir do referencial que se apresenta a seguir.

\section{Fundamentação teórica}

A atualidade pode ser entendida como uma relação do tempo o próprio tempo, ou, repensada a partir das novas tecnologias, como uma relação do tempo com a sua ausência. Uma intempestividade diacrônica onde a base fundante se encontra naquilo que, a primeira vista, não é presente ou percebido mas, simplesmente aceito e vivido.

É nesta atualidade que se encontra a educação formal tentando se perpetuar. Buscando docilizar e formar para os processos produtivos sujeitos que já nascem conectados. Tentando desenvolver as potencialidades daqueles que mal aprenderam a andar e já sabem destravar smartphones. Procurando transmitir uma herança cultural para meninos e meninas que possui praticamente toda informação criada durante o amadurecimento da humanidade na ponta de seus dedos. Este é um dos principais desafios imposto ao professor: trabalhar a partir de um modelo educacional historicamente instituído e perpetuado com sujeitos intempestivos e diacrônico em sua própria natureza.

Em 2004, Beatriz Sarlo (2004) alertava para o fim das cidades. Para a autora, os shoppings centers foram concebidos para substituí-la, uma vez que que os mesmos apresentavam novas maneiras de se compreender o cotidiano. Doze anos depois, pode-se afirmar que os shoppings não existem para os celulares que foram criados não só para substituí-los, mas também, para colocar a cidade, o mundo e todas as suas condições de experimentação nas pontas dos dedos. Assim, percebe-se que, agora, o mais importante não está mais "na face reflexiva do 
espelho. O interesse está na outra face, naquela que está coberta pelo nitrato de prata" (FLUSSER, 1998, p. 67). A rigor, esta é uma característica da atualidade: espelhos invertidos, cujo nitrato é justamente aquilo que possibilita a (inter) conexão entre o tempo e a sua ausência, ou, entre o concreto e o virtual. Entre as "paredes e as redes" (SIBILIA, 2012).

Com a possibilidade de desvendamento do universo nas palmas das mãos e, por outro lado, um modelo educacional secularmente instituído, emergem questões que merecem ser (re)pensadas como, por exemplo, a utilização das tecnologias em sala de aula. Em decorrência disso, torna-se possível afirmar que não basta, ainda enquanto exemplo, levar modernos equipamentos para a escola, como querem algumas propostas oficiais. Assim, não se faz suficiente adquirir televisões, computadores, tablets, entre outros, sem que haja uma mudança básica na postura do educador já que isto reduziria as novas tecnologias a simples meios de transmissão da informação. Logo, é preciso reinventar. Retirar a educação formal da prisão dos valores na qual ela foi forjada para que, desta maneira, se afaste o risco de perder seu sentido em detrimento da readequação de suas ações. Mesmo porque, conforme Petarnella (2011, p. 130):

O grau de novidade que se espera da escola é o ser passível de ressignificação para que, por meio dela, seja possível a transformação da paisagem do humano que, preso aos resultados das simbioses técnicas e tecnológicas que criaram a dependência humana à informação, vive em derivas.

É claro que esta reinvenção deve levar em consideração o espaço, tempo e a ausência de ambos no qual o modelo escolar opera. É certo também que "as novas tecnologias da comunicação e da informação permeiam o cotidiano, independente do espaço físico, e criam necessidades de vida e convivência que precisam ser analisadas no espaço escolar" (BRASIL, 2000, p. 11). Logo, se “os sistemas tecnológicos, na sociedade contemporânea, fazem parte do mundo produtivo e da prática social de todos os cidadãos [...]” (BRASIL, 2000, p. 12), entender o anacronismo ora apresentado se firma como um exercício inicial de concepção de possibilidades de reinvenção. Para tanto, o desvelamento de novas práticas educacionais, de novas formas de se enxergar e, ainda, de se educar pode estar encoberto pelas vozes daqueles que operam no cotidiano escolar, mas, muitas vezes, são silenciados pelo regimento ou pelo programa instituído de maneira hegemônica.

Aqui, tem-se ciência com Morais (2000, p. 17) que "indagações como estas fazem parte de nosso dia a dia enquanto docente, nos levando a questionar, reiteradamente, o porquê de tais 
“barreiras” para o professor". Tem-se consciência também que o professor não é o único agente da educação formal, apesar de comumente ser delegado a ele a responsabilidade pelo sucesso ou pelo fracasso do desempenho de alunos "digitais" forçados a operar no "modo analógico" educacional vigente. Aqui, vale lembrar que se trata de entender as novas tecnologias como novas práticas pedagógicas e não como novos instrumentos para as práticas secularmente instituídas. Trata-se também de entender que a reinvenção não significa ruptura, mas possibilidade de inovação adequada ao tempo no qual qualquer organismo opera.

Todo o dito implica no entendimento de que quando é falado na incorporação de tais tecnologias em sala de aula, bem como o próprio papel do professor nos afrontamos intrinsicamente com o desafio de adequarmos a educação a necessidade social atual. Mesmo porque, se vivemos em mundo totalmente digital, estamos na era da revolução tecnológica, e, ainda, quando se fala em revolução tecnológica, implicitamente encontra-se o fato de que a tecnologia transmuta diariamente e constantemente. Em decorrência disso, aqui pactua-se com algumas ideias de Guerreiro (2002, p. 36) para quem: “não se faz necessário somente os recursos tecnológicos. [Ao contrário]. Precisamos torná-los aliados sem perdermos sua essência identidade e afetividade".

Hoje a tecnologia já é parte inerente da vida humana, de modo que já não se consegue viver sem ela. Por outro lado, pode-se perceber que dos profissionais da educação, por mais que sejam capacitados, as céleres alterações tecnológicas têm exigido mudanças na sua forma de pensar e agir. Aliás, muitos não são favoráveis às mudanças no ensino, existindo, ainda, aqueles que não são favoráveis às tecnologias em sala de aula. Aqui, compartilha-se do mesmo entendimento de D'Ambrósio (2003, p. 1): “[...] atribuo essas atitudes a um excessivo conservadorismo e uma falta de visão histórica sobre como a tecnologia é parte integrante da sociedade e determina os rumos tomados pelas civilizações”.

Frente a urgência de se estabelecer o diálogo das práticas pedagógicas com as novas formas de ser e estar no mundo desvelados pelas tecnologias digitais, acredita-se na impossibilidade de ignorarmos tal fato. Ainda: Acredita-se que o uso das novas tecnologias da informação e da comunicação, no cotidiano escolar, podem e devem contribuir para a formação de professores e alunos. Em decorrência disso, este trabalho selecionou um entre vários recursos atualmente disponíveis para o fazer pedagógico como fio condutor e, ao mesmo tempo, indiciário para o desvendamento da compreensão docente sobre a utilização de recursos tecnológicos na 
atividade docente. Aqui, o recurso escolhido foi o Google Docs - um formulário eletrônico que possibilita o desenvolvimento de uma série de atividades em sala para além, é claro, de permitir o delineamento de práticas secularmente existentes sob uma nova ótica social.

A escolha deste recurso se deu a partir do entendimento com Antonio (2010), de que o educador quando se utiliza do recurso pedagógico propiciado pelo "Google Docs" acaba por operar com uma infinidade de possibilidades de uso pedagógico ou de suporte às suas atividades em sala de aula. Logo, se hoje existe a facilidade de aluno e professor acessar as informações, os conteúdos da disciplina, bem como, materiais de apoio às aulas por meio de vídeos e materiais disponibilizados via internet e, ainda, de recursos tecnológicos como computadores, celulares, smartphones, etc, o Google Docs se constitui, então, como uma disponibilidade didática e pedagógica presente para além dos muros escolares permitindo, assim, uma educação ampla e contínua que pode ser atualizada na medida em que se é acessada.

Foi considerada também, para a escolha do referido recurso, a possibilidade de se estabelecer uma prática pedagógica na "lacuna" entre o que já se têm amalgamado no cotidiano escolar e o que se espera do/no cotidiano escolar nesta nova configuração social. Isto porque, se atualmente o jovem é totalmente tecnológico e digital como revelam os dados da pesquisa realizada pelo Instituto Brasileiro de Geografia e Estatística, em 2015, e, ainda, conforme informações extraídas da mesma pesquisa, no Brasil, 90\% dos jovens de 9 a 17 anos possuem pelo menos um perfil em rede social (IBGE, 2015), estes mesmos jovens que acessam suas redes através do smartphone, poderiam, em tese, utilizar-se da mesma estrutura para realizar suas atividades acadêmicas. Sendo, então, o Google Forms um recurso facilmente acessado em qualquer tipo de aparelho, estes estariam instantaneamente e constantemente de posse de suas atividades.

Para amarrar todo o dito até o momento e, ao mesmo tempo, justificar o presente trabalho, cabe-nos informar que, segundo Camas (2012), este mundo no qual vivemos pode ser considerado como digital e que, portanto, a tecnologia faz parte do cotidiano de todos. Deste pertencimento emerge o desafio de se criar e dar vazão a uma nova escola, que vislumbre o currículo como o caminho a ser construído para e pelos aprendizes. Por novas tecnologias entende-se a convergência de tecnologias e mídias para um único dispositivo, que pode ser o notebook, o celular, o tablet, a lousa digital, o robô e quaisquer outras que surjam. Para o uso 
educacional, interessa particularmente a produção colaborativa de conhecimento, em que alunos e professores juntos também sejam coautores.

Ao refletir sobre os problemas e os desafios até aqui apresentados, chegou-se à conclusão de que seria, então, necessário dar vozes àqueles que operam no cotidiano escolar e que são os principais agentes do processo educacional que nele se estabelece: os professores. A partir da referida conclusão, buscou-se compreender como os mesmos entendem, percebem, atuam ou trabalham com o google forms em suas atividades ordinárias. Em decorrência disso, desvelou-se, então, a necessidade de se estabelecer um método que pudesse direcionar os trabalhos empíricos desenvolvidos e é, justamente, o referido que se apresenta a seguir.

\section{Metodologia}

É dentro de determinada realidade socio-histórica que os eventos ganham materialidade e significados. Para tanto, são nas relações entre o homem e a natureza, ou nas inter-relações entre o homem e a sociedade, que os significados se tornam passíveis de compreensão, sendo esta última oriunda de diferentes dinâmicas que, na especificidade deste trabalho, é abordada a partir da liberdade pela qual as mesmas ocorrem e pela profundidade em que devem ser interpretadas fazendo com que, em decorrência disso, este estudo se firme por meio da indução.

A coleta de dados foi realizada por meio de um questionário composto por sete questões abertas aplicados via google forms a 07 professores atuantes no ensino fundamental II da rede pública estadual do município de São Paulo/SP que, por sua vez, compuseram os sujeitos da pesquisa. Os referidos sujeitos formam um grupo heterogêneo no que tange o tempo de experiência no magistério, idade e área de atuação. Com idades que variam dos 38 aos 60 anos de idade e tempo de experiência entre 3 e 35 anos, os mesmos atuam nas disciplinas de Filosofia, Física, História, Biologia, Ciências e Matemática. A estes, foram realizadas as seguintes perguntas no questionário aberto:

1- Qual sua opinião sobre a inserção das tecnologias na sociedade?

2- Qual sua opinião sobre a inserção das tecnologias nas atividades docentes?

3- Qual(is) recurso(s) tecnológico(s) você acredita ser importante de ser disponibilizado aos docentes em sala de aula e por quê?

4- Qual(is) recurso(s) tecnológico(s) acreditariam ser importante de ser disponibilizado aos alunos em sala de aula e o porquê? 
5- Qual(ais) as maiores dificuldades ou barreiras encontradas por você ao usar tecnologia na sala de aula?

6- Qual(ais) as maiores dificuldades ou barreiras encontradas pelos seus alunos ao usarem tecnologia na sala de aula?

7- É possível o desenvolvimento de práticas pedagógicas baseadas exclusivamente nas tecnologias digitais de informação e comunicação? Por quê?

Optou-se por questões abertas por conta da natureza da pesquisa e de seus sujeitos. Por se tratar de professores envolvidos com o mote do presente trabalho, o objetivo central da mesma foi o de comparar a interpretação dos mesmos sobre dado fenômeno a partir de dada realidade social (FLICK, 2009). Os dados extraídos dos discursos dos professores foram analisados seguindo a técnica de Análise do Conteúdo preconizado por Bardin (2007). Aliás, para Chizzotti (2006), esta técnica pode utilizar, para o alcance de sua finalidade, documentos de diferentes origens e formatos que, aqui, se firmam como as respostas enviadas via google forms pelos professores.

$\mathrm{Na}$ análise dos dados foram consideradas três diferentes etapas inerentes ao material coletado. Na primeira, foi aplicado o questionário aos professores e verificadas suas opiniões sobre os temas pré-estruturados (VERGARA, 2005; FLICK, 2009). Nesta fase, optou-se por separar em blocos respostas por assuntos/contexto ao qual o mesmo se referia. Assim, por meio desta pré-análise (BARDIN, 2007), tonou-se possível conhecer, demarcar, formular e determinar o que deveria ser analisado e a forma pela qual a respectiva analise seria conduzida. Após a familiarização e a separação do material, a pesquisa caminhou para uma segunda fase, na qual foi realizada a exploração do material para a determinação das categorias de análise.

É importante ressaltar que nesta segunda fase os trechos extraídos dos questionários foram agrupados, constituindo-se, desta maneira, em Unidades de Significação (US). As unidades de significações permitiram que o material explorado pudesse ser agrupado e registrado a partir de sua significação. As Unidades de Significação foram compreendidas por meio da aproximação ou distanciamento de contextos, ideias ou terminologias (MYNAYO, 2001; TRIVINOS, 1987). Para tanto, os sentidos dos léxicos textuais, bem como, o deslocamento de grupos textuais a partir do contexto no qual o mesmo fora firmado, permitiram uma melhor compreensão e análise dos resultados explorados. Isto porque, ao fugir da interpretação quantitativa, muitas vezes trabalhada a partir da contagem de frequência de determinado termo, a pesquisa não segregou determinado 
fato ou termo de seu contexto tornando permissivo, desta maneira, explorar os fenômenos a partir de uma interpretação mais analítica de suas intercorrências.

Já em um terceiro momento, as Unidades de Significação constituíram-se em categorias de análise que, sob a ótica do referencial teórico, permitiram auferir os resultados da pesquisa empírica a partir da significação dos dados coletados (FLICK, 2009; CRESWELL, 2007). Os respectivos resultados puderam ser interpretados por meio do contexto no qual se buscou explorar e das contribuições que se desejou realizar. No caso em questão, entender como os professores têm enfrentado a inserção das tecnologias digitais no cotidiano escolar.

No processo de análise, os softwares Excel e Primitive Word Counter foram utilizados como ferramentas de auxílio para a composição das Unidades de Significação e das Categorias de Análise. Estas últimas, após criadas foram endereçadas ao software Wordlie que gerou, a partir da contagem da frequência de repetições do termo, uma nuvem de categorias cuja aquela que incidiu com maior frequência é apresentada com maior destaque e aquela com menor incidência, por sua vez, com menor destaque.

Uma vez que a análise do conteúdo possibilita, segundo Minayo (2001) e Bardin (2007), a descoberta de conteúdos que se ocultam frente a uma realidade latente, os dilemas e os problemas enfrentados no processo que buscou transformar as respostas dos professores na constatação de um problema que se torna tão importante quanto necessário seu enfrentamento, foram desvelados. Em decorrência disso, a análise e a discussão do referido conteúdo são apresentadas a seguir.

\section{Análise e discussão dos resultados}

A partir dos referenciais teóricos já explicitados neste trabalho, partiu-se para a análise das respostas dos entrevistados. Para tanto, optou-se por considerar cada questão, de maneira isolada, a partir das Unidades de Significação e sua posterior transformação em categorias de análise, para um melhor entendimento das questões inerentes ao entendimento coletivo dos respondentes. Assim, quando questionados sobre: Qual a opinião sobre a inserção das tecnologias na sociedade?, percebeu-se que as maiores frequências de conteúdo direcionaram o entendimento para as pessoas $(6,25 \%)$ e ajuda $(6,25 \%)$. Os demais termos, apesar de possuírem frequências abaixo dos $3,5 \%$, foram considerados para a composição das categorias de análise cujo resultado 
é apresentado em forma de nuvem onde os termos com maior incidência aparecem com um maior destaque na nuvem de palavras:

Figura 1- Categorias de análise sobre a inserção das tecnologias na sociedade

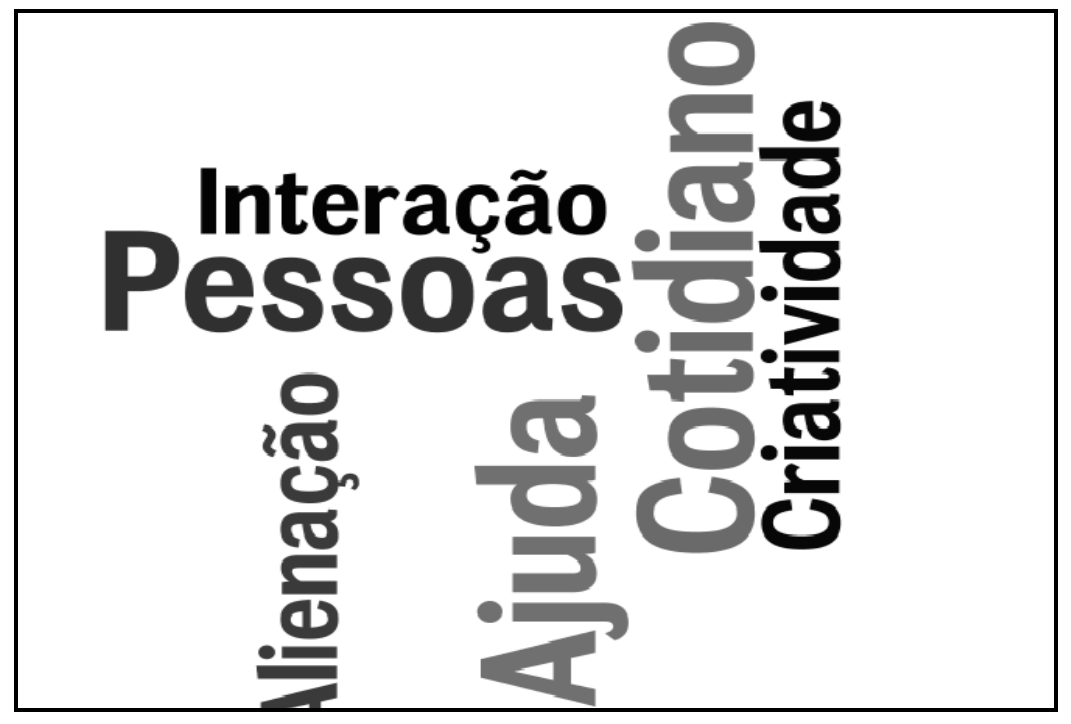

Fonte: Elaborado pelos autores.

A partir da nuvem apresentada, torna-se possível perceber que os professores associam a inserção das tecnologias na sociedade com as pessoas e com o cotidiano. Visualizam sua necessidade como mecanismo de auxílio para a realização de tarefas no dia a dia mas, ao mesmo tempo, emerge também um certo temor inerente a sua utilização. Aliás, a este respeito, torna-se importante trazer aqui o relato do respondente 03 quando diz que "Como toda criação humana, [a inserção das tecnologias se desvela como] uma faca de dois gumes: ajuda muito, mas pode escravizar, alienar, matar a criatividade”. Este posicionamento nos leva a questionar, então, como se dá o processo de escravização ou, ainda, a morte do espírito criativo, ou, ainda, como as mesmas poderiam ser utilizadas de maneira a não "matar a criatividade dos sujeitos" ou não os escravizá-los. Respostas a estas questões emergiram de maneira anacrônica ao analisar as respostas dos alunos que poderão ser vistas mais adiante.

Na mesma esteira do pensamento, quando questionados sobre: a inserção das tecnologias nas atividades docente, não foi possível fornecer organicidade às Unidades de Significação. Com respostas esparsas e, muitas vezes divergentes, a análise a este respeito só pode ser intuída. Por 
meio das categorias, a necessidade e o aprendizado se tornaram emergentes frente a possibilidade de melhoria ou, até mesmo, o próprio processo educacional. A nuvem formada pelas categorias de análise pode ser visualizada a seguir:

Figura 2 - Categorias de análise sobre a inserção das tecnologias na atividade docente

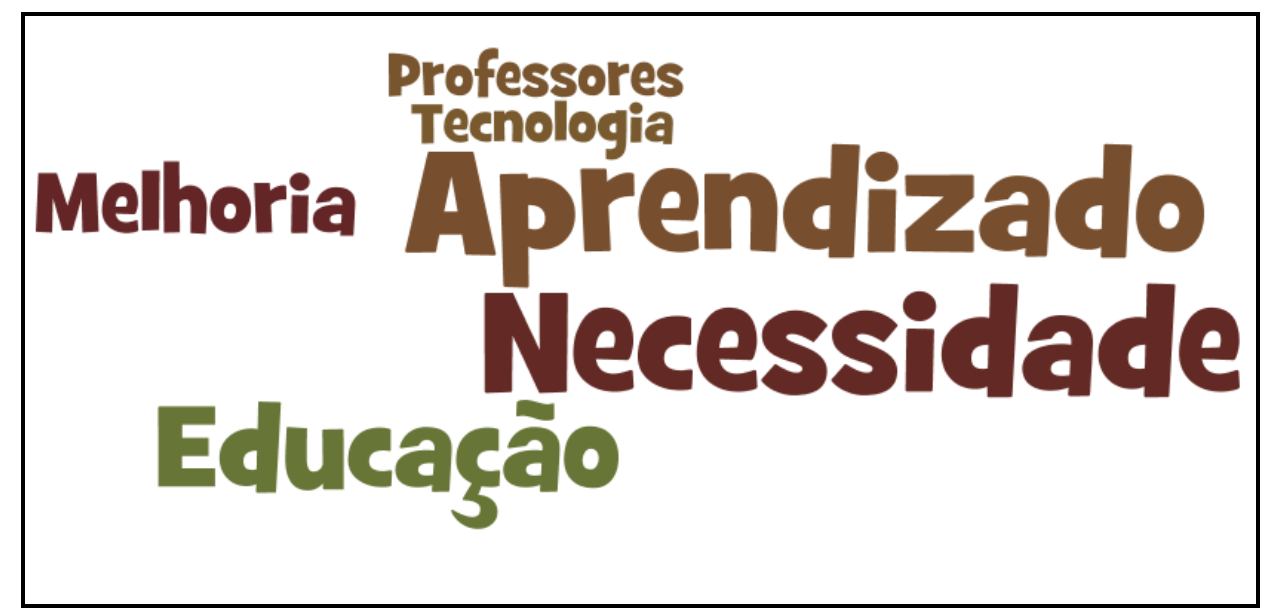

Fonte: Elaborado pelos autores.

Todos os respondentes, no que tange à referida inserção das tecnologias na atividade docente, se mostraram certos de sua necessidade. Ocorre que o apontamento do respondente 04 quando informa apenas que a mesma é "interessante”, associado ao entendimento do respondente 01 para quem a referida inserção é "positiva, desde que o professor esteja preparado para saber utilizá-las!", permite-nos refletir sobre a efetiva necessidade de aprendizagem docente para a sua utilização e sobre os temores inerentes às possíveis rupturas com as práticas educacionais secularmente instituídas. Mesmo porque, apesar da "qualidade da educação não depender só disso!’. Como afirma o respondente 01 em continuidade de sua resposta sobre a mesma questão e, ainda, apesar de "Einstein não [ter precisado] de muita tecnologia para elaborar a Teoria da Relatividade!" como o mesmo respondente afirma, sabe-se que cada tecnologia desvela a urgência de seu próprio tempo e, assim, o cuidado para com o desenvolvimento do processo educacional calcado nas tecnologias anteriormente instituídas para tal finalidade pode desvelar ou, até mesmo, justificar uma certa desconfiança sobre possíveis rupturas com as práticas educacionais secularmente instituídas. 
Ainda na mesma linha de análise, quando questionados sobre: Qual(is) recurso(s) tecnológico(s) você acredita ser importante de ser disponibilizado aos docentes em sala de aula e por quê?, os respondentes apontaram, de maneira dispersa, para diversos dispositivos informacionais. Entretanto, sem maiores especificidades ou associação a alguma prática docente. Assim, quando transformados em categorias de análise, pode-se perceber que a necessidade de recursos é evidente, mas claramente desassociados como dispositivos facilitadores dos processos de ensino e aprendizagem como preconiza a literatura que embasa o presente estudo. Aliás, com exceção do respondente 05, para quem os recursos servem "Para atualização e interação entre docente e alunos", para os demais, mesmo os computadores, data show, internet e recursos audiovisuais sendo considerados importantes de serem utilizados em sala de aula como aliados no processo ensino aprendizagem, estes não são visualizados como meios de desenvolvimento de novas práticas. Aliás, no contrapelo, por meio das respostas pode-se intuir que os mesmos se configuram como meras extensões de tecnologias secularmente instituídas como o giz e a lousa. A figura 3 nos permite uma melhor análise das categorias formatadas a partir das respostas à questão 3:

Figura 3 - Categorias de análise sobre os recursos tecnológicos a serem disponibilizados aos docentes

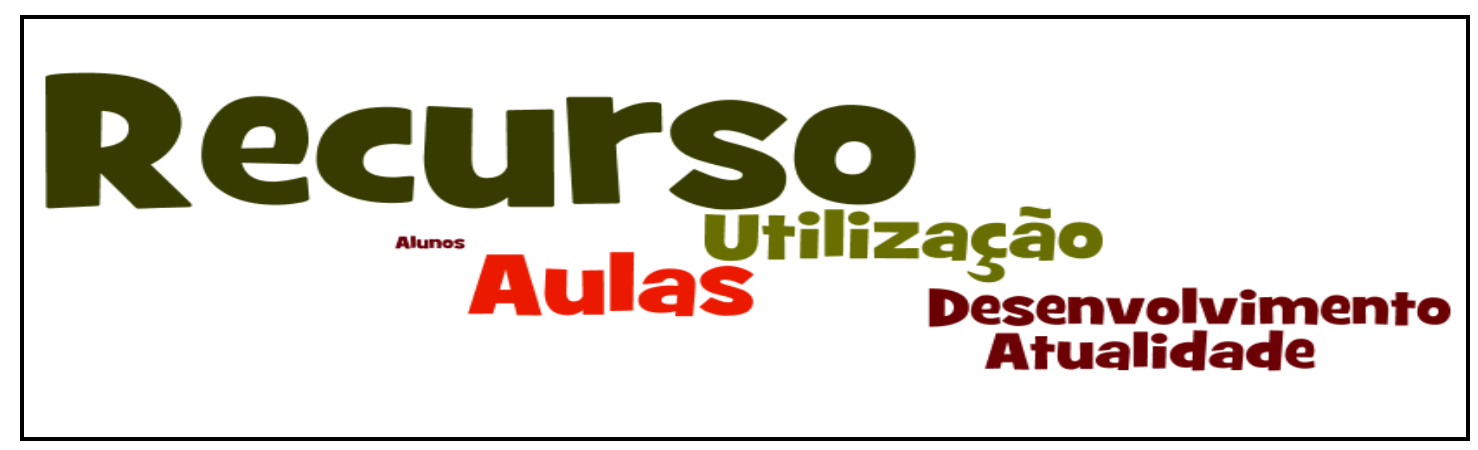

Fonte: Elaborado pelos autores.

A dispersão sobre o entendimento das necessidades dos recursos para o desenvolvimento da atividade docente, bem como sua efetiva aplicabilidade no cotidiano escolar, se arma e se mostra de maneira mais contundente a partir das respostas fornecidas a questão 4. Isto porque, quando questionados sobre: Qual (is) recurso(s) tecnológico(s) acreditariam ser importante de ser disponibilizado aos alunos em sala de aula e por quê? os respondentes que, por sua vez, possuem tempo de magistério que variam de 3 a 35 anos, forneceram espostas que indubitavelmente não 
permitiram o desvendamento com profundidade de sua intenção. Em outras palavras: as respostas não permitiram a constituição de Unidades de Significação e nem, tampouco, a constituição de categorias de análise para uma melhor interpretação do que se poderia entender a partir do discurso coletivo. A figura 4 apresenta com maior clareza a categorização das respostas para a referida questão:

Figura 4 - Categorias de análise sobre os recursos tecnológicos a serem disponibilizados aos alunos

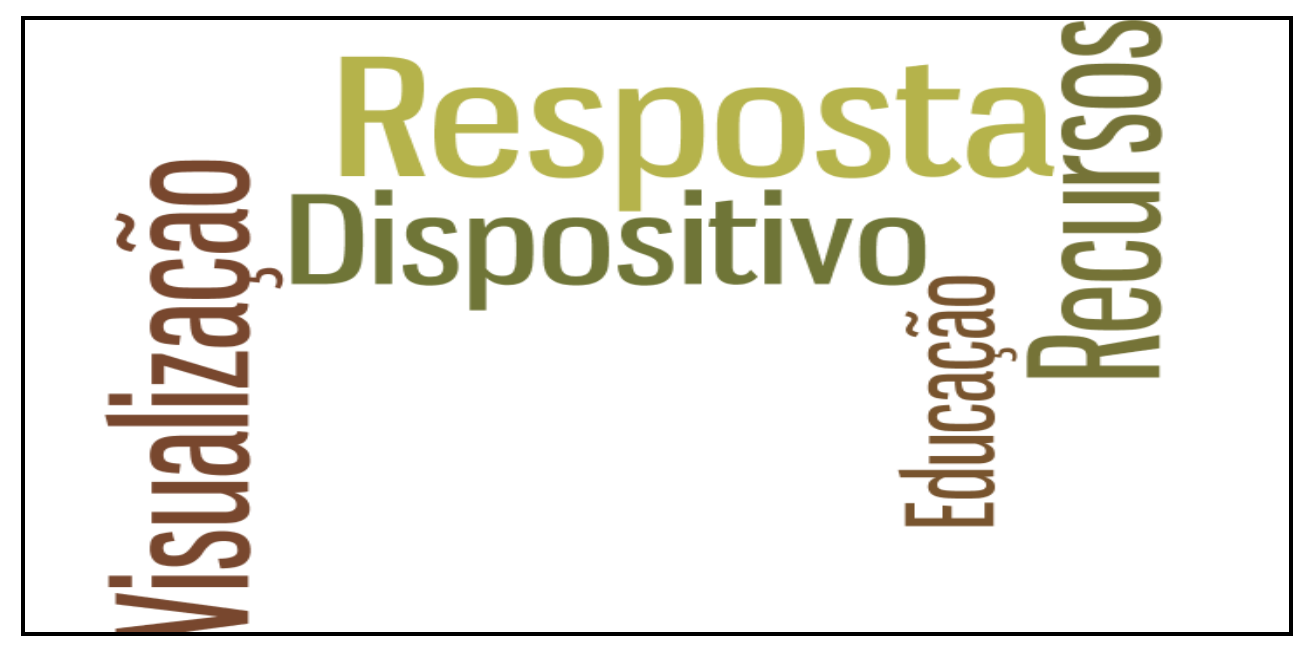

Fonte: Elaborado pelos autores.

Como pode ser visualizado na figura 4, as categorias de análise não remetem à questão elencada, o que, por sua vez, não permite desvelar se existe uma "crença" por parte docente de que, de fato, a utilização de algum tipo de recurso deva ser disponibilizado ao aluno. Em decorrência disso, mesmo com uma tecnologia cada vez nova e mais presente em nossa sociedade, nosso aluno que nos dias atuais está totalmente "conectado", por meio de mídias sociais, whatsapp, jogos digitais, deveria estar off-line no que tange à sua interação por meio das referidas tecnologias.

A rigor, todo o dito não implica em negar as mesmas em detrimento de um modelo baseado em técnicas mais tradicionais de ensino e aprendizagem e nem de assumi-las como o derradeiro caminho sem volta a ser seguido. Significa, em decorrência da dicotomia exposta, entender que os recursos tecnológicos digitais podem gerar condições favoráveis à educação auxiliando, inclusive, na existência de uma interação ais significativa entre aluno e professor 
exigindo, para tanto, a atualização pedagógica daquele que se propõe a desenvolver práticas pedagógicas alinhadas ao perfil destes alunos imersivos/virtuais (SANTAELLA, 2004). Ainda sobre esta questão, é importante salientar a resposta do respondente 06 que cita a tecnologia de "grafeno" como sendo uma forte aliada no processo ensino aprendizagem. Para este respondente, esta tecnologia é importante desde que exista um acompanhamento e preparação do educador. Para ele, "é importante a utilização de tecnologias como computadores, celulares e até a tecnologia com grafeno desde que haja um preparo do educador, do educando e da equipe de apoio”.

A unidade articuladora entre as necessidades docentes e as necessidades discentes a partir da visão dos professores começou a ganhar contornos mais definidos a partir da resposta à questão 5. Isto porque, ao serem questionados sobre: Qual(ais) as maiores dificuldades ou barreiras encontradas por você ao usar tecnologia na sala de aula?, ficou evidente que os mesmos vinculam a ausência de recursos, preparo dos docentes e falha na estrutura da escola, como potentes vertentes para tais dificuldades em sala de aula como pode ser observado na figura 5:

Figura 5 - Principais barreiras para a utilização das tecnologias em sala de aula pelo professor

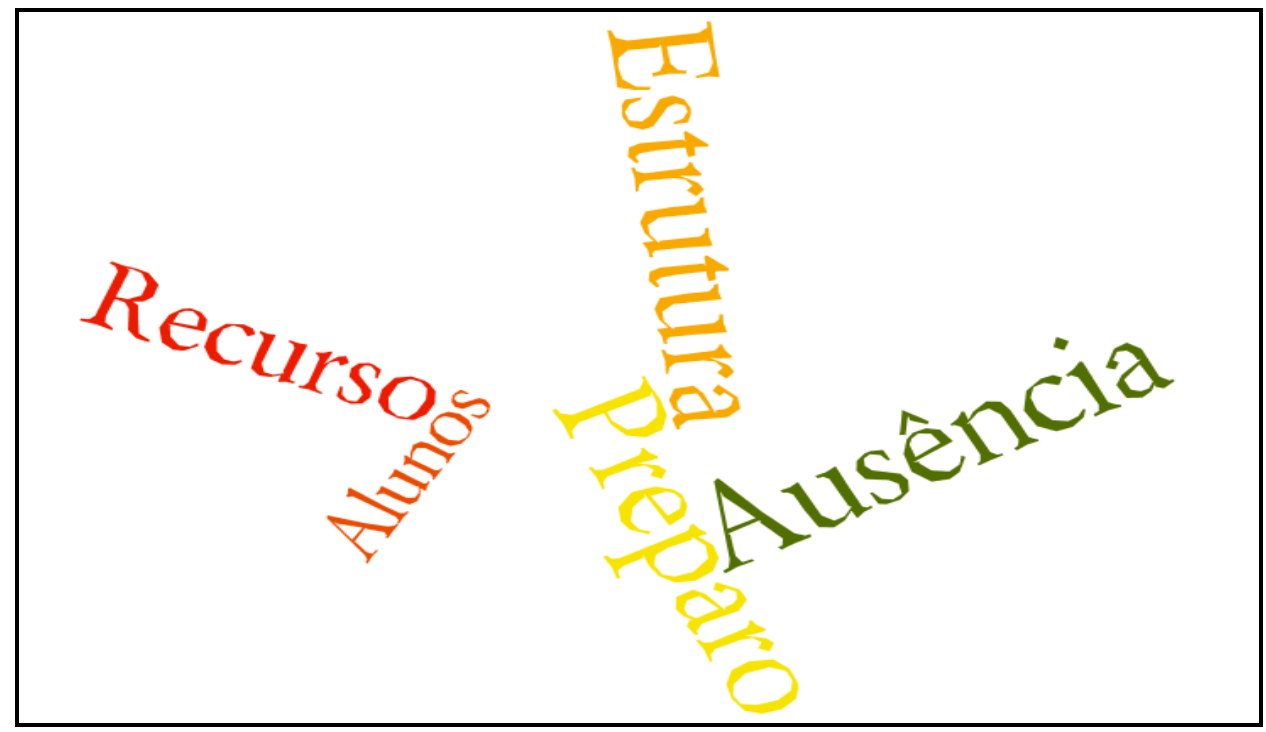

Fonte: Elaborado pelos autores.

As categorias de análise criadas a partir das Unidades de Significação das respostas à questão tornaram clara e contundente que a falta de estrutura, preparo e recursos dá a tônica do discurso docente. Aqui, o entendimento do respondente 03 para quem: "Falta de preparo dos 
recursos humanos, falta de material adequado e manutenção” se alinha aos dizeres do respondente 02 que afirma ser "A principal barreira a econômica. [e que ainda] é caro trabalhar com essas tecnologias. Sem falar na estrutura onde deverá ser aplicada e utilizada”.

O entendimento da importância das novas tecnologias na sociedade. O desenvolvimento de novas práticas docente com certa cautela no que tange os dispositivos tecnológicos, uma certa dispersão no que tange a disponibilização das mesmas para as atividades de ensino e um descompasso sobre a disponibilização destas para o processo de aprendizagem. Todas estas questões resumidas no despreparo, na ausência de recursos e estrutura, estariam, então, os professores denunciando um problema recorrente e já conhecido? Seria a maior dificuldade docente trabalhar com a alocação de uma grande quantidade de alunos por sala inviabilizando, assim, uma escola de qualidade e excelência? Estaria o respondente 04, que possui 34 anos de magistério, quando enfatiza que "A falta dos recursos, o número excessivo de alunos por classe (chega a ultrapassar os 40, o que torna inviável qualquer trabalho de qualidade)..." sinalizando que o atual sistema educacional não permite maiores preocupações docentes para além daquelas já urgentes, tais como, ensinar com o minimamente e humanamente possível e existente? As respostas a estas questões foram desveladas na medida em que as questões 6 e 7 foram respondidas. Afinal, quando perguntou-se, de maneira análoga aos professores, sobre: Qual(ais) as maiores dificuldades ou barreiras encontradas pelos seus alunos ao usarem tecnologia na sala de aula?, as respostas obtidas foram muito similares às dificuldades encontradas pelos próprios professores, conforme visualizado na figura 6 a seguir:

Figura 6 - Principais barreiras para a utilização das tecnologias em sala de aula pelo aluno

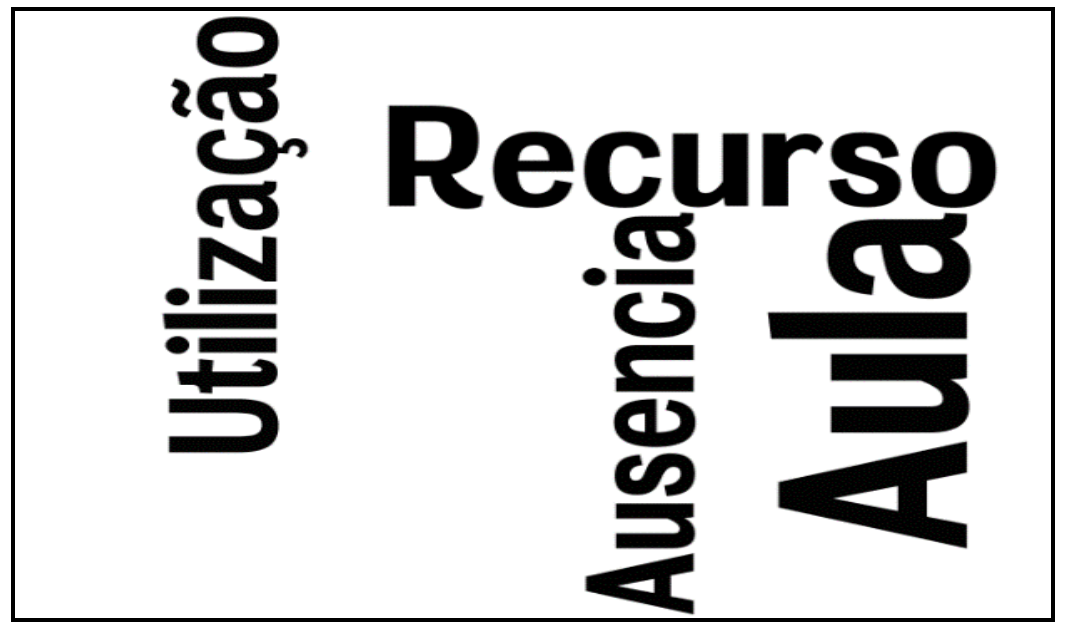

Fonte: Elaborado pelos autores.

Quaestio, Sorocaba, SP, v. 19, n. 3, p. 669-688, dez. 2017. 
De todos os relatos, a aula se constituiu como o eixo central para a análise. Em decorrência disso, a falta de recursos como internet, wi-fi e computadores suficientes em sala de aula, destacaram-se como principais barreiras encontradas. Esta constatação, nos permite afirmar então, que não existe barreiras para a utilização dos recursos. $\mathrm{Na}$ verdade, não existem recursos para serem utilizados. Entretanto, chama a atenção a resposta do respondente 04, com 38 anos de magistério, que acredita que o empecilho à utilização da tecnologia de maneira mais presente na educação é o preconceito e a não capacitação. Aqui, é importante considerar também que, para esta questão, o governo também se fez presente já que, para o respondente 02 , com 9 anos no magistério: "a principal barreira seria o incentivo em usar, por parte dos governantes. Pois na escola pública não temos condições de estrutura e nem infraestrutura para termos essas novas tecnologias. O poder público é ausente ainda”.

Foi justamente na constatação de que o discurso docente se enreda para a ausência de recursos, de preparo, bem como, para o preconceito e a falta de ações governamentais que se tornou possível encaminhar a presente pesquisa para a análise da última questão formulada. Para tanto, questionou-se os respondentes desta se: É possível o desenvolvimento de práticas pedagógicas baseadas exclusivamente nas tecnologias digitais de informação e comunicação? Por quê? As respostas, além de elucidar as questões levantadas nesta análise, permitiu ratificar a percepção que até aqui se delineou. Para um melhor entendimento desta questão, observe a figura 7:

Figura 7 - Possibilidade de desenvolvimento de prática pedagógica exclusivamente a partir das tecnologias

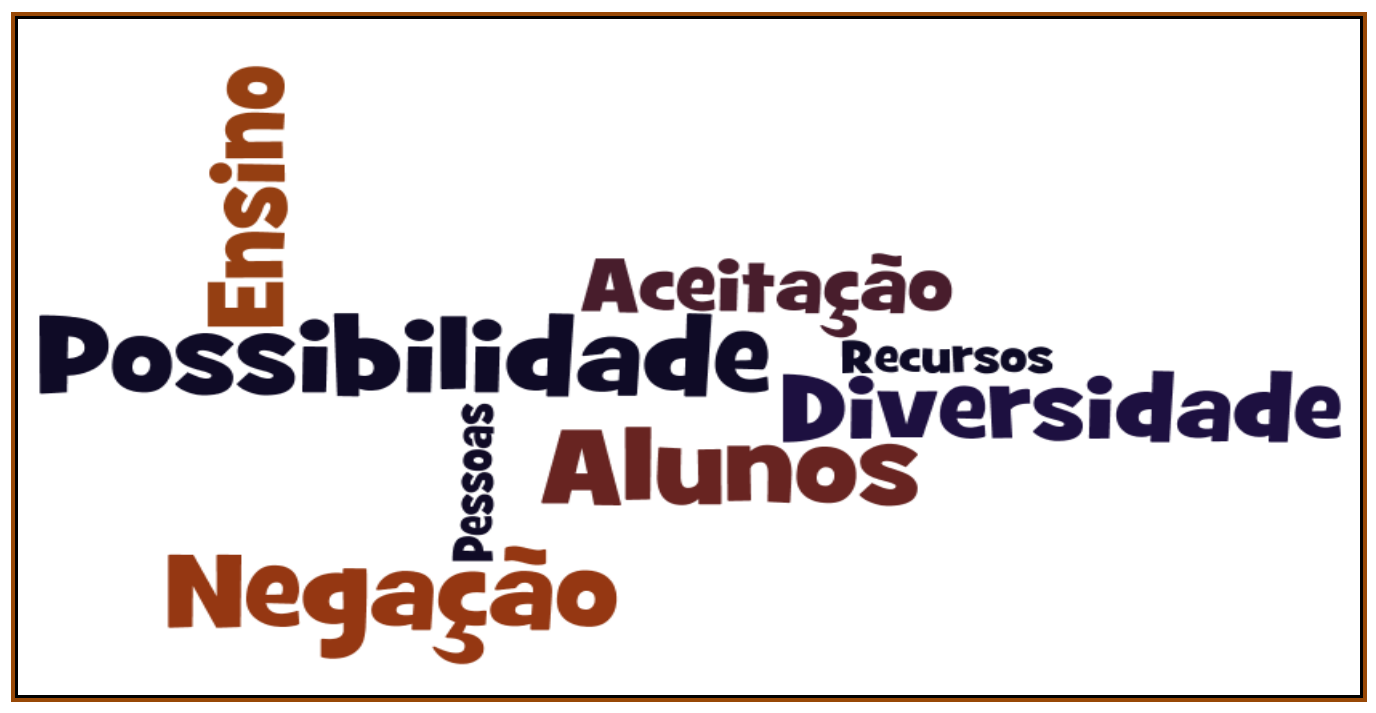

Fonte: Elaborado pelos autores.

Quaestio, Sorocaba, SP, v. 19, n. 3, p. 669-688, dez. 2017. 
Possibilidade e, ao mesmo tempo, negação. A dicotomia exposta se firma entre os professores com maior tempo de magistério e os com menor tempo. Estaríamos, então, desvendando uma crise entre gerações? As que, de um lado não acreditam que o desenvolvimento pedagógico fique pautado exclusivamente em tecnologia ou seja, para quem, é necessário haver interação pessoal, sendo, para tanto, a diversidade fundamental às práticas pedagógicas e, de outro lado, aqueles que visualizam nestas tecnologias novas possibilidades de se desenvolver o processo de ensino? Para o grupo de respondentes com maior tempo de magistério, a aceitação de recursos tecnológicos depende do surgimento de novas possibilidades para o ensino e de construção do conhecimento. Em decorrência disso, as tecnologias devem ser norteadas e controladas por essas diversidades e relações interpessoais entre aluno e professor. A este respeito o respondente 01 , com 35 anos no magistério público, é enfático: “Não, não acredito! Por mais que haja tecnologias de informação e comunicação, a relação pessoal e humana entre educandos e educadores é essencial; ainda não nos tornamos robôs! E se um dia nos tornarmos robôs, essa discussão não terá mais sentido! As máquinas não dão significado ao mundo e à vida!!!" Por outro lado, os professores com pouco tempo de magistério, entre 3 e 9 anos, acreditam que sim, o contexto pedagógico pode ser totalmente tecnológico. Já que, conforme relato do respondente 07: "Sim! Vivemos em um contexto urbano que deve possibilitar aos alunos outras possibilidades de aprendizagem. Um bom exemplo seria o curso de algumas disciplinas na modalidade EAD no Ensino Médio, preparando-os para uma realidade presente em diversas faculdades hoje”.

A partir das respostas a esta última questão elencada aos docentes, pode-se perceber que assim como o modelo educacional vigente, o discurso parece também ser secularmente instituído. Neste, destaca-se na fala dos professores a falta recursos para se desenvolver o processo educacional, mas ao mesmo tempo os mesmos não conseguem informar que tipo de recursos deva, de fato ser utilizado e, ainda, como deva ser utilizado no que tange as práticas de aula. Já sobre os alunos, a possibilidade de utilização dos referidos não é nem mesmo refletida. Sobre a importância de se desenvolver as atividades com a utilização das novas tecnologias, sobre a importância das mesmas, sobre as barreiras encontradas reverbera uma única síntese: mesmo sendo o reflexo da sociedade atual, as novas tecnologias, segundo os docentes, não devem ser vistas como questão central. Aliás, a este respeito, parece que até mesmo o desenvolvimento de possíveis práticas pedagógicas que utilizem as novas tecnologias de maneira criativa e criadora 
depende das ações governamentais e se configura, por isso mesmo, como um problema a ser resolvido pelo Estado.

\section{Considerações finais}

Uma criação humana que pode escravizar e eliminar a criatividade. Por isso, deve-se tomar cuidado. Estar preparado para utilizá-la. Mesmo porque, as maiores criações humanas não partiram ou se utilizaram delas. Logo, é importante que a mesma seja disponibilizada - o que é uma tarefa do Estado, mas não, necessariamente, que se as utilizem. É esta a síntese resultante do discurso docente sobre a inserção das cada vez mais novas tecnologias nas práticas pedagógicas.

Por outro lado, o mundo nas pontas dos dedos. As cidades sendo transformadas e operadas por aplicativos que permitem desde uma simples transação bancária ao estabelecimento de relacionamentos afetivos constituindo, desta maneira, uma zona intersticial cujas fronteiras não podem mais ser medidas ou determinadas fazendo com que as cabeças dos sujeitos hodiernos se configurem e se parametrizem de maneira digital.

A partir das determinações resultantes das reflexões sobre a percepção docente e dos dizeres dos referenciais teóricos se arma e se mostra um cenário que se atualiza a partir das novas possibilidades educacionais, mas que, ao mesmo tempo, reafirma o descompasso no qual o cotidiano escolar se estabelece: parece que os problemas e os desafios da inovação pedagógica é parte integrante de ações governamentais cuja responsabilidade não se apresenta àqueles que atuam no exercício da docência. Em decorrência disso, as possibilidades de novas práticas pedagógicas com recursos tecnológicos disponibilizados gratuitamente a todos que, por sua vez, permitem operar no tempo e espaço no qual os sujeitos hodiernos atuam, parecem estar longe da intenção das ações docentes ainda que, de maneira geral, já estejam preconizados nos Planos Curriculares Nacionais.

É claro que as amarras nas quais a educação formal se alicerça são rígidas. O que não significa, por sua vez, que não possam ser desatadas. Para tanto, retomando o pensar com Flusser (2008), se faz necessário duvidar da própria dúvida. Ou seja, estabelecer um elo de atenção entre o que se realiza e o que se espera. Espreitar o que se busca, enquanto resultado, e o que se desenvolve enquanto ação. É justamente a ausência deste estado de atenção que nos parece ser permissiva a definitiva conclusão de que apesar de existir a consciência docente de que vivemos 
em um período marcado pelas cada vez mais novas tecnologias, esta percepção acaba por formar uma falsa consciência da respectiva possibilidade de ação. Ainda: a falsa compreensão de que a inovação nas práticas pedagógicas é algo que depende da estrutura pública e, desta maneira, longe das reais possibilidades docentes.

A partir do exposto aqui, para definitivamente concluir com Nobert Elias (2011), se faz importante alertarmos que o descompasso apresentado pode estar amalgamado no distanciamento entre a situação histórica no qual se calça o trabalho docente do grupo que se reflete nela causando, assim, o estranhamento na base das experiências que deveriam ser comuns. Logo, o referido distanciamento enclausura as novas possibilidades e não permite que as práticas pedagógicas se reinventem. Elas "permanecem incolores, nunca se tornam plenamente vivas para aqueles que não compartilham tais experiências, que não falam a partir da mesma tradição e da mesma situação" (ELIAS, 2011, p. 25).

\section{Referências}

ANTONIO, José Carlos. Uso pedagógico do GoogleDocs, professor digital. 2010. Disponível em: <http://professordigital.wordpress.com/2010/02/08/uso-pedagogico-dogoogledocs/>. Acesso em: 8 fev. 2017.

BARDIN, Laurence. Análise de conteúdo. São Paulo: Edições 70, 2007.

BRASIL. Ministério da Educação e Cultura. Secretaria de Educação Básica. Parâmetros curriculares nacionais: ensino médio. Brasília, 2000.

CAMAS, Nuria Pons Villardel. Revisão teórica da ação pedagógica virtual. Revista EducaOnline, Rio de Janeiro, v. 6, n. 1, jan./abr. 2012. Disponível em: <http://www.latec.ufrj.br/revistas/index.php?journal= educaonline \&page=article\&op=view\&pat h[]=287>. Acesso em: 18 dez. 2014.

CHIZZOTTI, Antônio. Pesquisa qualitativa em ciências humanas e sociais. 3. ed. Petrópolis: Vozes, 2006.

CRESWELL, John W. Projeto de pesquisa: métodos qualitativo, quantitativo e misto. 2. ed. Porto Alegre: Artmed, 2007.

D’AMBRÓSIO, Ubiratam. Educação matemática: da teoria a prática. Campinas: Papirus, 2003.

ELIAS, Norbert. O processo civilizador: uma história dos costumes. 2. ed. Rio de Janeiro: Zahar, 2011. v. 1

FLICK, Uwe. Introdução à pesquisa qualitativa. 3. ed. São Paulo: Artmed, 2009.

FLUSSER, Vilém. Do espelho. In: FLUSSER, Vilém. Ficções filosóficas. São Paulo: Edusp, 1998.

FLUSSER, Vilém. A dúvida. São Paulo: Annablume, 2008.

GOOGLE. Vá além da edição de texto. Disponível em: <https://www.google.com/intl/pt-

BR/docs/about/>. Acesso em: 7 jan. 2017. 
GUERREIRO, Kátia Bomfim de Carvalho. Os profissionais da educação e as novas tecnologias - é possível funcionar sem “energia”?. 2002. Dissertação (Mestrado em Engenharia da Produção) Universidade Federal de Santa Catarina, Santa Catarina, 2002.

INSTITUTO BRASILEIRO DE GEOGRAFIA E ESTATÍSTICA - IBGE. Uso de celulares no Brasil. 2015. Disponível em: <www.ibge.gov.br/home/estatistica/populacao/acessoainternet/>. Acesso em: 8 fev. 2017.

MINAYO, Maria Cecília de Souza. (Org.). Pesquisa social: teoria, método e criatividade. 18. ed. Petrópolis: Vozes, 2001.

MORAIS, Gelcivânia Mota Silva. Novas tecnologias no contexto escolar. Revista Comunicação \& Educação, São Paulo, v. 6, n. 18, p. 15-21, maio/ago. 2000.

PETARNELLA, Leandro. Educação e cotidiano: a quarta idade da midiasfera. 2011. Tese (Doutorado em Educação) - Universidade de Sorocaba, Sorocaba, 2011.

SANTAELLA, Lúcia. Navegar no ciberespaço: o perfil cognitivo do leitor imersivo. São Paulo: Paulos, 2004.

SARLO. Beatriz. Cenas da vida pós-moderna: intelectuais, arte e videocultura na Argentina. 3. ed. Rio de Janeiro: Ed. UFRJ, 2004.

SIBILIA, Paula. Redes ou paredes: a escola em tempos de dispersão. Rio de Janeiro: Contraponto, 2012. TRIVIÑOS, Augusto Nibaldo Silva. Introdução à pesquisa em ciências sociais: a pesquisa qualitativa em educação. São Paulo: Atlas, 1987.

VERGARA, Sylvia Constant. Métodos de pesquisa em administração. São Paulo: Atlas, 2005.

Leandro Petarnella - Universidade Nove de Julho. São Paulo | SP |

Brasil. Contato: leandro_66@hotmail.com

Leandro Nhoncance - Universidade Nove de Julho. Contato: nhoncance@uni9.pro.br

Artigo recebido em: 16 mar. 2017 e aprovado em: 18 jul. 2017.

Quaestio, Sorocaba, SP, v. 19, n. 3, p. 669-688, dez. 2017. 